\title{
Fantasía y conciencia estética: El estatuto fenomenológico de la imagen
}

\author{
Ricardo Mendoza-Canales \\ Praxis - Centro de Filosofia \\ Universidade de Lisboa
}

Resumen: Este artículo busca establecer en primer lugar una doble distinción: de un lado, entre fantasía y conciencia de imagen; y, por el otro, entre fantasía y conciencia estética, ambas a partir de los trabajos de Edmund Husserl. Las dos series de distinciones se encuentran ligadas una con otra por el especial estatuto fenomenológico que Husserl concede a la imagen, el cual debe ser también sometido a aclaración. El artículo propone tres conclusiones: que la así llamada "conciencia estética" no es resultado de ninguna "epojé"; que la experiencia de la imagen entremezcla percepción y fantasía; y que esta conciencia estética ("imaginación" en sentido amplio) exige como contrapolo a un sujeto (un yo-imaginario) que habita en la irrealidad del "como si".

Palabras clave: Husserl; fantasía; conciencia estética; imaginación; conciencia de "como si"

Abstract: "Phantasy and Aesthetic Consciousness: the Phenomenological Status of the Image". This article aims to establish first a double distinction: on the one hand, between phantasy and image consciousness, on the other hand, between phantasy and aesthetic consciousness, both stemming from the works of Edmund Husserl. Both series of distinctions are connected by the special status that Husserl gave to the image, which is to be subject of explanation too. The article proposes three conclusions: that the so-called "aesthetic consciousness" is not the result of any Epoche; that the image experience intermingles phantasy and perception, and that this aesthetic consciousness ("imagination" in a wide sense) demands as its counter-pole a subject (the phantasy-Ego) who inhabits the irreality of the "as if". Keywords: Husserl; phantasy; aesthetic consciousness; imagination; as-if consciousness 
A lo largo de este artículo mostraré que la fantasía y la conciencia de imagen deben ser entendidas en una relación de género y especie. Desarrollaré esta idea en tres secciones. En la primera, mostraré cómo, si bien Husserl defendió hasta circa 1905 una concepción de la representación de fantasía como una forma de representación por medio de una imagen, los análisis expuestos en el curso de invierno de 1904-1905 (las Hauptstücke) muestran ciertas aporías que lo fuerzan a replantear su modelo. A continuación, en la segunda sección, se apreciará que, para Husserl, la estructura intencional de la fantasía será indesligable de la constitución temporal de los objetos en la conciencia interna. Por este motivo se hace evidente el importante rol que desempeña en la teoría de Husserl la neutralización, ya que su efectuación modaliza el carácter ponente o no ponente de los actos de fantasía, diferenciándolos. Por último, en la tercera sección, se estudia la llamada conciencia "estética" entendida en un sentido restringido: no en su sentido corriente como apreciación y valoración de una obra de arte, sino, antes bien, de las bases sensibles (y sus modalizaciones intencionales) que entran como componentes de la contemplación.

\section{Percepción, imaginación y temporalidad. El curso de invierno de 1904-1905}

Solo recientemente se cuenta con una panorámica completa del curso impartido por Husserl en el semestre de invierno del año 1904-19051. Esta limitación, restringida al trabajo de archivo hasta la publicación del volumen XXXVIII de la colección Husserliana, impidió durante largo tiempo comprender la unicidad no solo temática, sino también argumentativa del curso en su integridad. Las cada vez más citadas lecciones sobre la fantasía se inician sobre las adquisiciones metodológicas de las dos partes precedentes, a saber: i) que el acto más originario es el acto perceptual, pues se trata de una modalidad

\footnotetext{
1 Como lo consigna K. Schuhmann (Schumann, K., Husserks Chronik. Denk-und Lebensweg Edmund Husserls, Husserliana [=Hua] Dok I, La Haya: M. Nijhoff, 1981, p. 140), este curso, titulado Hauptstücke aus der Phänomenologie und Theorie der Erkenntnis in Vorlesungen und Übungen, nur für Fortgeschrittene [Partes principales de la fenomenología y la teoria del conocimiento, en lecciones y ejercicios, solo para (estudiantes) avanzados], fue ofrecido entre los meses de octubre de 1904 y marzo de 1905. Constó de cuatro partes: 1/ "Sobre la percepción" [Über Wahrnehmung] (Cf. Hua XXXVIII, Texto $\mathrm{N}^{\circ}$ 1); 2 / "Sobre la atención" [Über Aufmerksamkeit] (cf. Hua XXXVIII, Texto $\mathrm{N}^{\circ}$ 2); 3 / "Fantasía y conciencia de imagen" [Phantasie und Bildbewußtsein] (cf. Hua XXIII, Texto $\mathrm{N}^{\circ}$ 1); y 4 / "Sobre la fenomenología del tiempo" [Zur Phänomenologie der Zeit] (cf. Hua X, "Parte A").
} 
de intuición cuyas aprehensiones captan contenidos sensibles, en virtud de lo cual se pueden formular representaciones de objetos trascendentes a la conciencia; y ii) que un análisis fenomenológico debe poder desplazar el análisis a conciencia interna ${ }^{2}$. En otras palabras, la pregunta consiste en cómo solventar el pasar de una experiencia sensible externa a "reconducir" el análisis hacia la conciencia interna. Se trata de resituar la problemática en la órbita de la oposición receptividad/entendimiento. Como advierte Husserl en un pasaje ${ }^{3}$, la atención (Aufmerksamkeit) no está meramente ligada a una actividad de la pura espontaneidad: precisamente, su toma de distancia con Kant radica en que la atención únicamente se vuelve hacia su objeto cuando algo de este la reclama; incluso, la atención no se dirige como un rayo adánico hacia los objetos, sino que la captación visual nos ofrece ya una unidad o nexo de datos sensibles que lo componen, en la que lo atendido resalta en un primer plano, aunque los datos sensibles permanezcan, por así decirlo, en una suerte de "trasfondo" al que podemos orientarnos mediante la mención (Meinung).

Todo este marco tiene su punto de apoyo metodológico en el conocido esquema denominado "acto de aprehensión/contenido de aprehensión", del que creo necesario hacer una breve referencia. Considero que echar luz sobre este esquema permitirá aclarar los análisis husserlianos de la "representación" (Vorstellung), sea perceptual o de fantasía; un punto sobre el que pivotan los análisis efectuados a lo largo del curso del semestre de invierno de 1904-1905, esto es, las cuatro partes que lo compusieron. Según este modelo, ya empleado por Husserl en sus Investigaciones lógicas, toda vivencia intencional está basada en una estructura correlativa conformada por el mentar (meinen) y el objeto mentado. En cuanto al acto del mentar, este se conforma de momentos inmanentes: la aprehensión y el contenido de la aprehensión. El contenido se compone de los datos sensuales, mientras que la aprehensión "interpreta" (deutet) esos datos. Al tratarse de un contenido del nivel más inferior de la intuición (niedrigste Stufe), los datos sensuales por sí solos carecen de cualquier carácter intencional, es decir, de cualquier posible relación con un objeto. Únicamente la aprehensión es capaz de lograr, mediante una "interpretación" (Deutung) o "animación" (Beseelung) del contenido, una objetivación que devenga representación (Vorstellung) ${ }^{4}$.

\footnotetext{
Cf. Hua XXXVIII, p. 120ss.

Cf. Hua XXXVIII, p. 307ss.

4 A partir de 1907, Husserl comenzó a cuestionar la validez de este modelo para dar cuenta de la constitución temporal de los objetos en la conciencia interna, hasta llevarlo a su posterior
} 
Es teniendo como referencia a la conciencia de representación perceptual que Husserl formula la estructura de la conciencia de representación de la fantasía en lo que podría denominarse "etapa pre-trascendental" de su fenomenología. En el opúsculo de 1898 sobre la fantasía y la representación imaginante (recogido como Anexo 1 al Texto $\mathrm{N}^{\circ} 1$ de Husserliana XXIII), Husserl busca profundizar en la relación entre las representaciones perceptuales y las representaciones de fantasía. Estas últimas serían propiamente presentificaciones ${ }^{5}$, si bien siempre apoyadas sobre una imagen que le sirva de medio: de allí la presunción de continuidad entre la representación de imagen (Bildvorstellung) y la representación imaginante o mediante imagen (bildliche Vorstellung).

En la representación de imagen intervienen tres elementos: la imagen física (physisches Bild), el objeto-imagen (Bildobjekt) y el tema de la imagen (Bildsujet) ${ }^{6}$. La aprehensión de cada una depende de la orientación de la contemplación (Betrachtungsrichtung). El ejemplo que emplea para ilustrar esta idea, que fue posteriormente repetido en la tercera parte del curso de 1904$1905^{7}$, es el de una fotografia. Resumidamente: el papel fotográfico, esto es, el soporte material, es la imagen física; las líneas, formas, colores, pigmentos, la disposición espacial de los trazos, todo ello configura el objeto-imagen; por último, lo que se entrevé, la figura que surge, es decir, la persona que vemos en la fotografia, es el tema-de-la-imagen ${ }^{8}$.

\footnotetext{
"abandono" un año después. $c f$. Hua X-B, Texto $\mathrm{N}^{\circ}$ 39; Hua XXIII, Texto $\mathrm{N}^{\circ}$ 8; y Hua Mat VII, 146ss. Pero, como advierten Lohmar ( $C f$. Lohmar, D., "Die Entwicklung des husserlschen Konstitutionsmodells von Auffassung und Inhal", en: Studia Univeristates Babeş-Bolyai. Philosophia, v. LIV, 2 (2009), pp. 3-19) y Conde Soto (Conde Soto, F., Tiempo y conciencia en Edmund Husserl, Santiago de Compostela: Servizio de Publicacións da Universidade de Santiago de Compostela, 2012, pp. 78-80 y 88ss.), este "abandono" es apenas relativo. Podría decirse que dejó de tener carácter teórico para pasar a tener mero carácter metodológico. El modelo siguió siendo empleado implícitamente por Husserl para concebir de la estructura de la intención, independientemente de cómo sean dados esos contenidos (si presentados o presentificados).

5 A lo largo del artículo, emplearé los términos "presentificación" para verter al castellano el vocablo alemán Vergegenwärtigung y "presentación", para Gegenwärtigung. Asimismo, he optado por traducir el vocablo alemán (de raiz latina) Repräsentation por "re-presentación" (y a veces, ligeramente modificando a Gaos y Morente, por "re-presentación funcional"). Dejo de lado, pues, la elección propuesta por Antonio Zirión de "re-presentación" para Vergegenwärtigung. El motivo reside en reservar el término técnico de "representación" para Vorstellung, así como para distinguir a este último de la Repräsentation. Dado que Husserl emplea ya este término en sus escritos de la década de 1890 para designar genéricamente a las objetivaciones mediante imagen propias de la presentificación, a partir de 1904 su uso permanecerá asociado a las representaciones figurativas de los actos de fantasía y, tras Ideas I, caerá en desuso por ser subsumido como el contenido referencial del nóema.

6 Hua XXIII, p. 109.

7 Hua XXIII, p. 19.

8 Hua XXIII, p. 109.
} 
Es sabido que, en 1904, Husserl mantenía aún una posición "realista" que confería una primacia a las intuiciones perceptuales por su naturaleza "en presencia" (leibhaftig), esto es, la actualidad de los contenidos sensibles (perceptivamente captados) sobre otras formas de representación. La lógica subyacente del análisis de Husserl en esta etapa concebía el paradigma de la representación imaginante como basado en la estructura de la intuición perceptiva. De allí que hasta ese momento Husserl todavía defendiera la idea de la imaginación basada en una "doble aprehensión". La analogía se configura del siguiente modo. Siguiendo siempre el esquema "acto/contenido", por un lado, en la primera aprehensión, hay una imagen fisica que aporta la materia sensible y da como resultado el objeto-imagen. La segunda aprehensión surge de la contraposición entre figuración (Abbildung) y exhibición (Darstellung), esto es, del paso del objeto-imagen a la representación de un objeto ausente (no actual o no presente), el Bildsujet: el objeto re-presentado (repräsentiert) por medio de la imagen. Siguiendo esta misma lógica, los recuerdos serían "imágenes sin presencia"; la imaginación, "imágenes sin soporte material". Ambos son, del lado del acto intencional, presentificaciones; del lado la representación objetual, re-presentaciones (Repräsentationen).

Es este precisamente el punto de partida de las lecciones sobre la fantasía y conciencia de imagen de 1904-1905, pero no su conclusión. Dicho en otras palabras: Husserl se propuso analizar fenomenológicamente la validez de esta misma idea, pero inscrita en un marco mucho más amplio y ambicioso desarrollado a lo largo de las cuatro partes del curso ${ }^{10}$.

Para el tema que me ocupa, conviene atender sobre todo la última parte de dichas lecciones. Tras haber ido analizando de modo regresivo las condiciones que diferenciarian una intuición perceptual de una presentificada, Husserl pasa a examinar la posibilidad de situar la distinción en los contenidos de la aprehensión: o bien sensaciones (Empfindungen), captadas "en presencia"; o bien fantasmas [Phantasmata], presentificadas. En este punto surge el problema de las fantasías "claras" y "oscuras"11. Lo que ocurre es que la claridad u opacidad de la fantasía depende del origen sensible del que esté elaborada: ambas son presentificaciones, pero las primeras son "claras" porque su origen reside en una intuición perceptual presente (leibhaftig), esto es, son datos de sensación que en virtud de su marca impresional incorporan sus caracteres

9 Cf. Hua XXIII, pp. 109ss.

${ }^{10}$ Hua XXXVIII, p. 1.

${ }^{11}$ Hua XXIII, p. 79ss. 
de creencia (y, por tanto, son ponentes) que son presentificados. Por su parte, las fantasías "opacas" o, con más precisión, "no-claras" (unklare) se erigen sobre una base sensible "desacreditada" (diskrediert), esto es, al que, en virtud de una modificación, las posiciones de creencia han sido "desactivadas"12. El problema, entonces, se vuelve a desplazar: de la percepción externa pasamos a la conciencia de dicha intuición, que se conforma a partir de una actividad de la conciencia que se dirige a su objeto. Sin embargo, esto no explicaría la diferencia entre un paisaje efectivamente visto (en el presente o en el pasado) y uno meramente imaginado, ni mucho menos explicaría por sí solo el problema del conflicto que surge de la imposibilidad de solapamiento entre dos campos visuales, uno efectivamente percibido y el otro fantaseado. Husserl advierte que no se trata meramente de una diferencia entre actos de aprehensión (uno perceptual y otro imaginativo, como había resuelto alrededor de 1898). Esta es la razón por la que es necesario desplazar el análisis fenomenológico al nivel más inferior de la aprehensión, los contenidos, ya que ello implica la temporalidad del dato sensible en su inscripción en el flujo de la conciencia.

En la cuarta parte del referido curso de 1904-1905 -la dedicada a la fenomenología del tiempo interno- Husserl "desciende" en sus análisis, por así decirlo, a la descripción de los contenidos sensibles que al inscribirse en la corriente de conciencia como puntos-ahora (Jetzt) son modificados en retenciones. La proto-impresión (Urimpression) no es, por tanto, ninguna representación propiamente dicha. Se trata de los contenidos "mínimos" que, según este modelo "acto/Contenido de aprehensión", son "interpretados" en el acto objetivante. Es en este punto que Husserl, elaborando sus ideas a lo largo del curso de invierno, propone la idea de la "doble intencionalidad": una intencionalidad longitudinal, que recoge las sintesis de modificaciones impresionales en el flujo del presente viviente; y una intencionalidad transversal, que tiende a las sintesis de los nexos de retenciones. La diferencia entre actos perceptuales y actos rememorativos radica en la orientación que adopta cada una de estas dos intencionalidades. Asimismo, partiendo de la base de la primordialidad de la intuición perceptual, Husserl postula que la posicionalidad (Positionalität) inherente a la proto-impresión se debe precisamente a la actualidad del acto de aprehensión. Así pues, debido a su naturaleza "actual" ("en presencia", leibhaftig), incorpora el carácter ponente (setzende), esto es, la creencia (belief) procedente de la plenitud impresional del punto-ahora. Del mismo modo, dado

${ }^{12}$ Hua XXIII, p. 102.

ARETÉ Revista de Filosofía, v. XXXII, 1, 2020 / ISSN 1016-913X 
que los actos rememorativos "traen a la conciencia" -si bien bajo la forma de una presentificación- nexos retencionales captados perceptualmente en un estadio temporal anterior, estos deben traer necesariamente consigo sus propios caracteres de creencia: por eso "creemos" en lo que recordamos.

A partir de entonces, Husserl va abandonando poco a poco la perspectiva inicial según la cual las representaciones de fantasía deben ser interpretadas como conciencia de imagen. Si todavía la diferencia entre representaciones perceptuales y el resto de representaciones de fantasía se puede establecer (ya con cierta precariedad) como una diferencia entre los contenidos de las aprehensiones, este marco se vuelve indefendible por dos motivos cuando se trata de distinguir la diferencia entre los diferentes modos de representación de fantasía (por ejemplo, la rememoración [Wiedererinnerung] o la fantasía pura). En primer lugar, porque estas representaciones tendrian que ser derivadas de un acto perceptual originario que devenga acto de base (fundante) y, por tanto, deberían ser siempre reproducciones de nexos de retenciones (y sus "colas de cometa"). El problema con esyo es el siguiente: cada uno de estos puntos retencionales es resultado de una primera modificación retencional (por la cual la impresión originaria es convertida en "recuerdo fresco", en el lenguaje de 1905), por ende, no son "actuales", sino que han de ser presentificados; y si la presentificación fuera una representación imaginante (como se desprendería del modelo descrito lineas arriba), entonces las retenciones deberían ser ellas mismas una representación mediante imagen, lo cual conduce a un contrasentido ${ }^{13}$. En segundo lugar, porque si la diferencia solamente recayera en los contenidos de esas aprehensiones (perceptuales y de fantasia, respectivamente), surgiría entonces la posibilidad del conflicto entre campos visuales incompatibles debido a sus modos de donación (como presente actual y realmente efectivo frente a la irrealidad del objeto-imagen que se constituye como conciencia de imagen), lo que también conduce a un contrasentido. Este impasse solo comenzará a ser resuelto a partir del descubrimiento de la reducción fenomenológica y la consiguiente reflexión de la conciencia sobre sí.

Este es, sucintamente, el camino que describen las Hauptstücke y que revelan su rol clave en el tránsito hacia la fenomenología trascendental. Si bien es

\footnotetext{
${ }^{13}$ No deja de resultar sorprendente que un lector tan entrenado y de la talla de Paul Ricoeur haya llegado a esta precipitada e ingenua conclusión, acusando a Husserl de haber propuesto equiparar los recuerdos con imágenes. Lo más llamativo es que se apoya en volúmenes de la Husserliana (entre los que cita los volúmenes III, VIII, X, XIII y XXIII) demostrando ser, a pesar de su frondosa erudición, una lectura sesgada, inexacta y bastante desinformada. Cf., Ricoeur, P., La Memoria, la historia, el olvido, Madrid: Trotta, 2003, pp. 67-75).
} 
importante remarcar que los resultados alcanzados en este periodo (1904-1905) no constituyen una solución definitiva de esta problemática, ya que Husserl continuó perfeccionando su teoría durante al menos las dos décadas siguientes, sí debe tenerse en cuenta que, para él y en adelante, todo el tratamiento relativo a la intuición perceptual y las distintas modalidades de la fantasía (incluyendo a la conciencia de imagen) son indesligables de -y han de ser abordadas junto con- el problema de la temporalidad de la conciencia ${ }^{14}$.

\section{Vivencia de fantasia y conciencia constituyente: la escisión del yo}

La conversión trascendental de la fenomenología es indesligable del descubrimiento de la conciencia interna del tiempo. Ello tuvo un impacto significativo en la concepción husserliana acerca de la imaginación y la fantasía ${ }^{15}$. A partir de 1912, Husserl explícitamente identifica la fantasía con toda conciencia de presentificación ${ }^{16}$. Conviene subrayar que no toda representación presentificante (vergegenwärtigende Vorstellung) es una fantasía "pura". Es preciso distinguir entre actos presentificantes reproductivos y actos presentificantes no reproductivos. Los actos presentificantes reproductivos son ponentes (como la rememoración, la expectativa o la empatia), mientras que los actos presentificantes no reproductivos son no ponentes. Entre estos últimos es preciso distinguir, a su vez, entre fantasías perceptivas (perzeptiv), como en el caso de la conciencia de imagen, y las fantasias "puras" (modificadas "de punta a punta"). Lo que distingue a cada uno de estos actos presentificantes es el modo de dación (Gegebenheitsmodus) ${ }^{17}$.

\footnotetext{
${ }^{14}$ Para una explicación detallada acerca de los dos tipos de modificaciones que se llevan a cabo en la presentificación (la posicional, relativa al emplazamiento temporal en el flujo de conciencia que es "hecho presente" mediante la modificación reproductiva, y la dóxica, relativa al carácter de creencia, esto es, la modificación de neutralidad). $C f$., Mendoza-Canales, R. "Estructura intencional y libre fantasía en Ideas I de Edmund Husserl", en: Anales del Seminario de Historia de la Filosofia, v. XXXVI, 2 (2019), pp. 421-439.

${ }^{15}$ Para un tratamiento sistemático de este tema, $c f$. Aldea, A.S., "Husserl's struggle with mental images: imaging and imagining reconsidered", en: Continental Philosophy Review, 46 (2013), pp. 371-394; Carreño Cobos, J., "The Many Senses of Imagination and the Manifestation of Fiction: A 100 View from Husserl's Phenomenology of Phantasy", en: Husserl Studies 29, 2 (2013), pp. 143-162; De Warren, N., “Tamino's Eyes, Pamina's Gaze: Husserl's Phenomenology of Image-Consciousness Refashioned", en: Ierna, C., Jacobs, H. y F. Mattens (eds.), Philosophy, Phenomenology, Sciences. Essays in Commemoration of Edmund Husserl, Phaenomenologica 200, Dordrecht: Springer, 2010, pp. 303-302; Jansen, J., "Phantasy's Systematic Place in Husserl's Work", en: Bernet, R., Welton, D. y G. Zavota (eds.), Edmund Husserl. Critical Assessments of Leading Philosophers, v. III, Londres/Nueva York: Routledge, 2005, pp. 221-243; Shum, P., "The Evolution and Implications of Husserl's Account of the Imagination", en: Husserl Studies 31, 3 (2015), 213-236.

${ }^{16}$ Cf. Hua XXIII, p. 322; Hua VIII, p. 113.

${ }^{17} C f$. Hua XXIII, p. 324ss y, especialmente, p. 475ss.
} 
En lo que a este tema respecta, el análisis husserliano de la conciencia de fantasía a partir del "descubrimiento" de la reducción fenomenológica y de la distinción de la doble intencionalidad de la conciencia interna lo conduce a postular dos instancias constituyentes. Por un lado, se reconoce un yo-actual (Reales-Ich), que es quien, en la actualidad de la corriente de vivencias, efectúa la fantasía; por otro lado, se reconoce un yo-fantaseado (phantasiertes Ich), que es quien "vive" en lo fantaseado, la conciencia o polo constituyente del objeto de la fantasía. El primero es el polo-egoico de la cuasi-percepción, mientras que el segundo es el polo-egoico de la propia vivencia de fantasía. A esto Husserl lo denominó "Ichspaltung": una "escisión del yo". Es importante remarcar que esta escisión, sin embargo, no debe ser confundida con una duplicación de la conciencia. No se trata de dos conciencias o alter ego que realizan sus operaciones simultáneamente, operando así al mismo nivel, sino de una conciencia (la conciencia actual) que, sin perder su anclaje con la realidad (en sentido ordinario), "se escinde" en dos niveles de efectuación distinta, cada una con una estructura intencional temporalmente interna ${ }^{18}$. En tanto que modificación de conciencia, el yo-imaginario (Phantasie-Ich) "es una irrealización de la conciencia", una "(auto)trascendencia al interior de la inmanencia": "[A]1 inducir una semejanza de mi propia actividad perceptual, estoy para mí mismo en una manera que es otra respecto a como yo realmente hago experiencia de mí mismo"19.

El análisis fenomenológico de la fantasía revela esta doble instanciación. Desde un punto de vista "estático", por medio de la reflexión, la conciencia (actual, pero fenomenológicamente reducida) se vuelca sobre sí, de modo tal que el acto de fantasía deviene el propio objeto de la intuición. La conciencia actual se dirige hacia su "objeto", que no es sino la vivencia presentificada. Pero esta vivencia presentificada demanda una atención hacia lo que en ella misma se manifiesta, y es este rendimiento el que ha de ser constituido intencionalmente por el yo-imaginario: "La conciencia de la re-presentación, que se denomina representación (de la fantasía) de un objeto, no es la representación de una

\footnotetext{
${ }^{18}$ Para una exposición detallada acerca de la "escisión del Yo", cf. Bernet, R., Conscience et existence, París: PUF, 2004 (en especial, pp. 112-117); Cavallaro, M., "The phenomenon of Egosplitting in Husserl's phenomenology of pure phantasy", en: Journal of the British Society for Phenomenology 48, 2 (2017), pp. 162-177; y Luft, S., "Die Konkretion des Ich und das Problem der Ichspaltung in Husserls phänomenologischer Reduktion”, en: R. Kühn y M. Staudigl (eds.), Epoché und Reduktion: Formen und Praxis der Reduktion in der Phänomenologie, Würzburg: Königshausen \& Neumann, 2003, pp. 31-49.

${ }^{19}$ De Warren, N., Husserl and the promise of Time, Cambridge: Cambridge University Press, 2009, p. 157.
} 
conciencia de algo del ser-ahí-mismo del objeto, sino la representación del ser-ahí-mismo. Si reflexiono sobre la conciencia de la re-presentación, sobre la representación de fantasía, entonces eso es algo actualmente percibido, un ahora"20.

Sin embargo, ¿ se aplica esta estructura no solo a las fantasías "puras" sino también a toda conciencia de presentificación (en sus variadas formas: recuerdos [Erinnerungen], expectativas [Erwartungen], imágenes [Abbildungen], etcétera)? A fin de responder esta interrogante, hace falta examinar un ejemplo: el recuerdo de la lámpara que tenía hace un año sobre mi mesa. Esta lámpara tenía una forma, un color, ocupaba una extensión de mi mesa y emitía un determinado tipo de luz. Cuando se estropeó, y ante la imposibilidad de repararla, tuve que comprar una nueva. En mi mesa "actual", sobre la que escribo estas palabras, veo la nueva lámpara: ella es captada sensiblemente con sus cualidades (extensión, color, peso, etcétera) y es evidentemente distinta de la vieja lámpara. Efectúo una rememoración: recuerdo la disposición espacial de mi mesa (la misma mesa, con los mismos libros sobre ella, situada igualmente junto a la ventana) y "veo" la imagen de la lámpara vieja. Hay una imposibilidad de superposición entre ambos objetos (la lámpara rememorada y la lámpara actual, que capto perceptiblemente): ambas no pueden ocupar simultáneamente el mismo campo visual y extensión espacial en el presente. Solo mediante un acto de presentificación (en este caso específico, una rememoración) puedo "ver" mi mesa, los libros, la ventana y la lámpara vieja, pero no se trata de ninguna presentación. En mi presente vivo, en mi corriente de conciencia donde se asienta mi yo actual, mi conciencia se orienta hacia contenidos del pasado (recuerdos), pero no por ello "vivo en el pasado": sigo viviendo en el presente. Esos contenidos mentados, no obstante, deben ser interpretados (deuten) para constituir el objeto "lámpara vieja". Pero el objeto "lámpara vieja" no es un objeto que forme parte de mi presente perceptivo porque no lo estoy viendo. El objeto "lámpara vieja" exige, pues, una conciencia ante la cual y para la cual ella aparezca constituida como objeto.

Parece claro que se trata de dos conciencias (una "conciencia de pasado" y una "conciencia actual"), pero esto, por sí solo, no determina la diferencia entre un acto rememorativo y un acto de fantasía. El fundamento último de

\footnotetext{
20 "Das Bewusstsein der Repräsentation, das Vorstellung (der Phantasie) vom Gegenstand heisst, ist nicht Vorstellung vom Bewusstsein vom Selbstdasein des Gegenstandes, sondern Vorstellung vom Selbstdasein. Reflektiere ich auf das Bewusstsein der Repräsentation, auf das Phantasievorstellen, so ist das ein aktuell Wahrgenommenes, ein Jetzt” (Hua XXIII, p. 177).
} 
la diferencia entre ambos tipos de actos reside en la conciencia inmanente (o interna). Si, por un lado, la rememoración y la fantasía (pura) comparten el hecho de ser presentificaciones intuitivas (anschauliche Vergegenwärtigungen); por otro, se distinguen en el tipo de conciencia (actual en un caso, inactual en el otro) en la que los actos presentificantes son cumplidos. Los actos rememorativos corresponden a intenciones cumplidas del pasado vividas, en aquel emplazamiento temporal, por un yo actual bajo la forma de intuiciones perceptuales. Así, lo rememorado forma parte de la propia "historia" del sujeto toda vez que sus intenciones fueron inscritas en el flujo temporal de la conciencia del yo (Ichbewusstsseinsstrom) bajo una forma impresional. En el ejemplo, la lámpara es primero captada como un objeto trascendente (percepción externa) e inscrita originariamente con un emplazamiento (position) en el flujo de conciencia interna. Además, el mundo en el que dicha lámpara vieja fue captada se corresponde con el mundo actual en el que vivo conscientemente: no se trata de dos realidades disociadas; antes bien, se trata de una misma orientación de la conciencia, dirigida a la misma espacialidad (percepción externa), que captó objetos (Gegenstände) con sus escorzos, su entorno co-lateral inatendido y su horizonte ${ }^{21}$. Estos objetos son dados a la conciencia junto con su emplazamiento temporal (Zeitlage) individual en el flujo de la conciencia interna ${ }^{22}$. De alli la necesaria identidad entre el objeto que fue efectivamente percibido en el pasado (pero que entonces era ahora actual) y su recuerdo actual por medio de su rememoración. Un acto rememorativo, por tanto, involucra la coincidencia (Deckung) entre ambas conciencias (la actual y la rememorativa), puesto que de este modo se fundamenta la unidad y el encadenamiento (Kette) entre el pasado y el presente de la vida efectiva de la conciencia ${ }^{23}$. Pero esta coincidencia no ocurre en los actos de fantasía. Dicha síntesis resulta imposible debido precisamente a que la fantasía provoca una escisión del yo (Ichspaltung), pues segrega, de la conciencia actual (yo real), una conciencia que hace experiencia de sus objetos en una cuasi-temporalidad ${ }^{24}$ (yo-imaginario).

\footnotetext{
${ }^{21}$ Para una explicación más detallada acerca de la estructura de la atención, cf. Serrano de Haro, A., "Pain Experience and Structures of Attention: A Phenomenological Approach", en: van Rysewyk, S. (ed.), Meanings of Pain, Dordrecht: Springer, 2016, pp. 165-180 (ver esp. pp. 166-168) y Scanziani, A., "Intencionalidad y atención: el abordaje husserliano de la atención en relación con la intencionalidad y su caracterización como 'mentar", en: Ideas. Revista de filosofia moderna y contemporánea, 7 (2018), pp. 48-82.

${ }^{22}$ Hua XXXIII, p. 328ss.

${ }^{23}$ Hua XXXIII, p. 334.

${ }^{24}$ Es importante subrayar que el prefijo que Husserl emplea, "cuasi-" (quasi-), no quiere decir que algo sea deficitario, falso o inferior a lo real. Simplemente significa que es "equivalente a" y posee
} 
Volcados en la fantasía, la representación de fantasía se constituye para una conciencia de fantasía (Phantasiebewusstsein). La aprehensión del objeto imaginario conlleva una especie de "percepción no-real" ya que se encuentra "vaciada" de sus caracteres fácticos sin que ello signifique que, en tanto que experiencia individual que posee su propia espacio-temporalidad (cuasi-temporalidad y cuasi-espacialidad), vaya acompañada de su carácter de creencia (una cuasi-creencia). Sin embargo, al acto de fantasía le es propio tener una duración limitada: el objeto fantaseado y el yo-imaginario que lo fantasea solo duran lo que dura el acto; y cada vivencia de fantasía carece de vínculo esencial unas con otras ${ }^{25}$.

En el acto de fantasear se "ve" algo (el objeto fantaseado): "En la fantasía, la aparición es puesta como una 'percepción' para el yo-imaginario"26. Lo que es traído a experiencia es dado en la modalidad del "cuasi-" (una cuasi-percepción, un cuasi-juicio, etcétera) ${ }^{27}$ : "Toda la conciencia, que es casi como en la percepción real (wirkliche Wahrnehmung), re-presenta funcionalmente (repräsentiert) la conciencia de la percepción real"28. En la conciencia de fantasía, los objetos se encuentran "como si estuvieran" (gleichsam) presentes. Aparecen, se muestran de una u otra manera, desde un ángulo, de alguna forma, etcétera, pero la aparición no es como la de la aparición perceptual (la presentación originaria). Sin embargo, la conciencia de fantasía es una conciencia que opera en el "cuasi": "La conciencia de la fantasía no es percepción, sino 'como si fuera' percepción. La conciencia entera es presentificada y es re-presentante" 29 . Presentificar un objeto, por tanto, no significa exclusivamente presentificar la percepción por la cual el objeto fue captado. Este es un detalle importante a tener en cuenta para lograr el máximo esclarecimiento del problema.

La fantasía es entonces una modificación general de la conciencia que convierte la experiencia al modo del "como si". Los actos intencionales en ella plenificados conforman sus objetos sobre la base de contenidos que fueron dados bajo la forma del presente (las sensaciones) o de la presentificación (fantasmas). Como afirma Husserl: "Una fantasía es o bien inmediata modi-

unas características homólogas.

${ }^{25}$ Hua XXXIII, p. 336 y p. 351.

26 "[I]n der Phantasie wird die Erscheinung dem Phantasie-Ich als Wahrnehmung eingelegt" (Hua XXIII, p. 174).

27 Hua XXIII, p. 341.

28 Hua XXIII, p. 178.

29 "Das Bewusstsein der Phantasie ist nicht Wahrnehmung, sonder gleichsam Wahrnehmung. Das ganze Bewusstsein ist vergegenwärtigt und ist Repräsentant” (Hua XXIII, p. 175). Énfasis mío. 
ficación de fantasía de una percepción -fantasía del presente- o bien ella es fantasía del pasado o [fantasía] del futuro. En este último caso, ella es modificación de fantasía de un recuerdo. Un recuerdo solamente es posible en un nexo de conciencia que implica un presente dado originariamente: el propio recuerdo es originariamente un acto presente. Una modificación de fantasía de un recuerdo solamente es posible en un nexo de fantasía que implica una conciencia de fantasia del presente como dado quasi originariamente. Y esto vale tanto para una remembranza como para una anticipación (expectativa)"30.

La fantasía no es pues, ella misma, solamente conciencia de imagen. La conciencia de imagen (o imaginación en sentido amplio) es apenas una de las formas o subtipos de la fantasía.3.

\section{Conciencia estética y el estatuto fenomenológico de la imagen}

Como se vio en la sección anterior, la fantasía no es propiamente una conciencia de imagen, sino que esta última es apenas un sub-tipo de la primera: más concretamente, una fantasía perceptiva (perzeptive Phantasie). Que la conciencia de imagen sea un sub-tipo de la conciencia de fantasía implica que los contenidos no actuales (los fantasmas) de la intuición deben ser dados a una conciencia que no es ni puede ser coincidente con la conciencia actual: en otras palabras, no cabe la posibilidad de una sintesis de solapamiento entre ambos yoes. Una representación inactual (esto es, bajo la forma del cuasi-) no puede ser dada en la esfera de una conciencia actual porque ello supondría una confrontación o conflicto (Widerstreit) con las intuiciones perceptuales: "El conflicto separa, por así decir, el yo actual y el yo fantaseado"31. En otras palabras, las presentificaciones (por ejemplo, un recuerdo, una expectativa o una fantasía "pura", sin anclaje en el presente actual de su captación) se sobrepondrian a las presentaciones ${ }^{32}$.

\footnotetext{
30 "Eine Phantasie ist entweder unmittelbare Phantasiemodifikation einer Wahrnehmung, Gegenwartsphantasie, oder sie ist Vergangenheits- oder Zukunftsphantasie. Im letzteren Fall ist sie Phantasiemodifikation einer Erinnerung. Eine Erinnerung ist nur möglich in einem Zusammenhang des Bewusstseins, der Gegenwart originär gegeben impliziert, die Erinnerung selbst ist ein originär gegenwärtiger Akt. Eine Phantasiemodifikation einer Erinnerung ist nur moglich in einem Phantasiezusammenhang, der ein Phantasiebewusstsein der Gegenwart als quasi originär gegeben impliziert. Und das gilt für Rückerinnerungen ebenso wie für Vorerinnerungen (Erwartungen)" (Hua XXIII, p. 532).

31 "Der Widerstreit trennt sozusagen aktuelles und phantasiertes Ich" (Hua XXIII, p. 173, n.1).

32 Cf. Hua XXIII, pp. 173. Para un desarrollo extensivo sobre la noción de conflicto y su relación con la imaginación en Husserl, cf. Ferencz-Flatz, C., "Gibt es perzeptive Phantasie? Als-ob-Be-
} 
Una fantasía pura es una presentificación de algo enteramente no presente, modificada "de punto a punta" (durch und durch), esto es, no una mera reproducción derivada de una impresión originaria ${ }^{33}$. Sin embargo, en el caso específico de la conciencia de imagen, no se trata únicamente de una neutralización de la percepción (que convertiría lo percibido en mera "imagen"), sino que se trae algo no-presente (en el ejemplo ya propuesto en 1904-1905: el rostro de una fotografia) al presente sobre la base de una percepción actual (el papel fotográfico): hay, por tanto, una mezcla de percepción y fantasía. Esa imagen es igualmente una presentificación, pero no es meramente reproductiva ${ }^{34}$. Para pasar del nivel de los contenidos sensibles de la percepción (el papel fotográfico) a la "presencia" inactual (presentificada) de la persona que reconocemos en la imagen, hace falta: primero, neutralizar el carácter de creencia del primero (la imagen fisica); segundo, "sumergirse" en las formas que sobre ella se imprimen (el objeto-imagen: Bildobjekt); y tercero, "conformar" el objeto que emerge o aparece (el tema-de-la-imagen: Bildsujet). Respectivamente, la modificación de fantasía es efectuada por la conciencia actual ${ }^{35}$. El objeto-imagen es constituido por una modalización de la conciencia propia de fantasía como una cuasi-vivencia, mientras que el tema-de-la-imagen es una efectuación del yo-fantaseado (o yo-imaginario). Por lo demás, al subrayar que la fantasía es una modalización del carácter ponente inherente a la creencia, se hace visible la diferencia metodológica que cumplen la epojé y la modificación de neutralidad 36: "Cómo se sitúa la separación del objeto-imagen y el tema-de-la-imagen

wusstsein, Widerstreit und Neutralität in Husserls Aufzeichnungen zur Bildbetrachtung”, en: Husserl Studies 25, 3 (2009), pp. 235-253.

${ }^{33}$ Frente a la idea expuesta en Ideas de la fantasía como una modificación neutralizada de un recuerdo (fantasía como neutralización de una conciencia reproductiva impresional), Husserl ya había postulado que el concepto de la fantasía (equivalente en sentido general a "presentificación") posee dos formas fundamentales: fantasía como presentificación reproductiva y fantasía como presentificación perceptiva (Hua XXIII, 476 y 591]. En la primera, la presentificación reproductiva, un objeto se capta "como si [als ob] estuviera alli", pero no lo está "en persona" [leibhaftig]). En la segunda, se trata de apariciones [Erscheinungen] vacidas de su carácter tético (esto es, no ponentes), una presentificación apenas como mera imagen. Afirma Husserl: "Se deben separar estas modificaciones de aquellas que transforman la posición en una no-posición. (Inter-

106 sección de ambas distinciones). Además, no se debe confundir las percepciones [Perzeptionen] no-ponentes con vivencias que exponen figurativamente; esto es, con presentificaciones" (Hua XXIII, pp. 475-476 [Texto $\mathrm{N}^{\circ} 16$ ], traducción mía).

${ }^{34}$ Cf. Hua XXIII, p. 467ss. Ver también: Bernet, R., Kern, I. y E. Marbach, An Introduction to Husserlian Phenomenology, Evanston: Northwestern University Press, 1993, p. 152

${ }_{35}$ Como el propio Husserl reconoce (Hua III/ 1, p. 250; Husserl, Ideas I, 2013, p. 345), toda modificación de fantasía es una modificación de neutralidad, pero no toda modificación de neutralidad es una modificación de fantasía.

${ }^{36}$ Sobre la diferencia metodológica fundamental entre la epojé y la modificación de neutralidad, cf. Mendoza-Canales, R., "La fenomenología como teoría del conocimiento: Husserl sobre la epojé 
dependerá mucho de un correcto análisis de la conciencia de imagen. Yo puedo constituir el objeto-imagen y 'verlo' como un objeto en el espacio ordinario. Por otro lado, el tema [de la imagen], en genuina conciencia interna, no es pues dado a la consciencia de modo reproductivo, sino "visto". Es imaginado, pero perceptivamente imaginado" 37 .

¿Es entonces una conciencia de fantasía lo mismo que una conciencia estética? Se ve claramente que no es lo mismo percibir que apreciar estéticamente un objeto. La diferencia radica en el "interés" o, como distingue Husserl, entre el interés por la aparición (Interesse an der Erscheinung) y el interés por el tema (Interesse an der Sache) ${ }^{38}$. Por ejemplo, un ingeniero captará sensiblemente una extensión de terreno a fin de medirlo, analizarlo topográficamente, ver sus elevaciones y depresiones. Un excursionista amante de la naturaleza se detendrá a apreciar el mismo terreno desde otra perspectiva. Ambos captan sensiblemente el mismo terreno, pero lo que guía su interés es distinto. Uno estará guiado por un interés "teorético"; otro, por un interés meramente "estético". No se trata aún de ninguna valoración atribuida, sino simplemente de marcar una diferencia respecto del modo como ambos objetos son dirigidos: "Si el objeto aparece en esta o aquella orientación es irrelevante para la toma de posición temática, para la [toma de posición] dirigida a él, a este idéntico objeto, 'que lo valora'. Pero ello no es irrelevante estéticamente. La valoración estética está relacionada con la distinción entre la conciencia de un objeto en general y el modo de aparición del objeto. Cada objeto del cual se tiene consciencia está dado a la conciencia en un modo de aparición; y el modo de aparición puede pues ser el que determina una conducta estética: la que en uno caso [determina] un placer estético; en el otro, un desplacer, etc."39.

\footnotetext{
y la modificación de neutralidad", en: Revista de filosofia, v. XLIII, 1 (2018), pp. 121-138. De otro lado, acerca de la carta de Husserl a Hoffmansthal y para una crítica a la linea interpretativa que homologa la modificación de neutralidad con la epojé, $c f$. Mendoza-Canales, R., "Ver y no creer: imaginación, fantasía y conciencia de 'como si' en la fenomenología de Husserl", en: Phainomenon, 27 (2018), pp. 69-97.

37 "Es wird sehr viel ankommen auf eine korrekte Analyse des Bildbewusstseins, wie es mit der Scheidung von Bildobjekt und Bildsujet steht. Ich kann das Bildobjekt konstituiren und als Objekt im gewöhnlichen Raum „sehen“. Andererseits ist doch das Sujet im echten inneren Bildbewusstsein nicht reproduktiv bewusst, sondern "gesehen“. Es ist imaginiert, aber perzeptiv imaginiert" (Hua XXIII, p. 481).

${ }^{38}$ Cf. Hua XXIII, p. 145ss.

39 "Ob der Gegenstand in der oder jener Orientierung erscheint, das ist für die sachliche Stellungnahme, für die auf ihn, diesen identischen Gegenstand, gerichtete, ihn „wertende“ einerlei. Es ist aber nicht ästhetisch einerlei. Ästhetische Wertung hängt wesentlich zusammen mit dem Unterschied zwischen Bewusstsein eines Gegenstandes überhaupt und Erscheinungsweise des Gegenstandes. Jeder Gegenstand, indem er bewusst ist, ist in einer Erscheinungsweise bewusst,
} 
Contemplar un objeto estéticamente involucra, en primer lugar, un ejercicio sensorial: los sentidos entran necesariamente en juego. Así pues, en la base de toda contemplación estética reside un entramado de intuiciones perceptuales: si nos limitamos a una obra de arte, esta no se deja reducir únicamente a uno de nuestros sentidos. Dicho en otras palabras: al apreciar una pieza teatral ${ }^{40}$, vemos el escenario y a los actores en movimiento, oímos las voces y reconocemos su entonación, entendemos los parlamentos como en cualquier conversación y también son significativos las luces, las sombras, la música, los atrezos sobre escena, incluso hasta es posible emplear olores para formar una atmósfera. Una obra es una compleja trama sensorial ligada a capas significativas de sentido. Como decía, la contemplación estética presupone una base perceptiva: no hay contemplación sin los sentidos. Pero lo sensorialmente captado es apenas la base material sobre la cual, como se vio en la sección anterior, lo allí sentido deviene otro objeto en virtud de una modificación de la creencia. Este otro objeto, captado como imagen (y aquí imagen no se restringe únicamente a lo visual: recordemos que ya Saussure, inspirado en las Investigaciones lógicas de Husserl, habla de "imagen acústica") es mentado por nosotros como un "cuasi" en una conciencia de "como si".

¿Cuál es entonces la relación entre la fantasía y la "conciencia estética"? Esto nos conduce al siguiente punto, relativo al estatuto fenomenológico de la imagen.

Para Husserl, la distinción fundamental entre una captación "visual" y una "imagen" no reside en la naturaleza de sus contenidos, sino del modo como la conciencia trata con ellos. De allí que el estatuto fenomenológico concierna fundamentalmente al cómo (wie) aprehendemos un objeto (en este caso, la imagen) y, por tanto -y correlativamente-, cómo se da este a la conciencia. Para el caso de un análisis más propio del arte, sin duda la imagen se convierte en un poderoso vehículo de significación (si bien esta significación no se limita exclusivamente a, ni procede de, la imagen misma, sino que debe incluir también a las valoraciones que hunden sus orígenes y motivos en la vida de la conciencia). Aquí cabría distinguir además si se trata de imágenes estáticas o en movimiento. Pero en cualquiera de ambos casos, estamos ante una "conciencia de imagen"

und die Erscheinungsweise kann es nun sein, die ein ästhetisches Verhalten bestimmt, die eine ein ästhetisches Gefallen, die andere ein ästhetisches Misfallen usw" (Hua XXIII, p. 388).

${ }^{40}$ Husserl emplea el ejemplo de la representación teatral para analizar aquel tipo particular de ficcionalización que escinde para el sujeto la experiencia del mundo real y el del mundo de fantasia, que posee su propia temporalidad ( $c f$. Hua XXIII, Texto $\mathrm{N}^{\circ} 18 \mathrm{~b}$, pp. 514-524). 
(pero teniendo en cuenta que esa conciencia constituyente no es ni puede ser la conciencia "actual”). La característica principal de la conciencia de imagen radica en que ni el objeto-imagen ni el tema-de-la-imagen son coincidentes con la objetivación propia de los contenidos sensibles. Dicho en otras palabras: no "vemos" los materiales físicos ni constituimos el objeto únicamente sobre la base de la sintesis de los datos sensibles. "Ver" un cuadro como tal no es ver su soporte material (el lienzo, el marco que lo rodea y que limita la mirada, etcétera), sino la figuración que emerge de los colores y las formas allí exhibidas. Del mismo modo, tampoco contemplar un paisaje es simplemente "ver" los elementos que lo componen (un cúmulo de árboles, una montaña, el sendero que desciende de la montaña, los campos sembrados, etcétera). Antes bien, es la experiencia neutralizada de todos esos elementos y de una modalización de la conciencia constituyente que, en conjunto, emergen para componer una imagen que pueda conmover (si nos quedamos en la mera apreciación "estética"). ¿Qué quiere decir entonces aquí "experiencia neutralizada"?

Un mismo objeto visualmente formado puede servir tanto como una intuición perceptual (un objeto ahî), como una imagen desanclada de cualquier interés teorético. Es este último punto, ese "desinterés", el que conlleva la neutralidad de la imagen. Para Husserl, la neutralidad de la imagen exige suspender el carácter ponente de la nóesis, "liberando" así su correlato noemático: "[L]a modificación de neutralidad de la percepción normal, ponente con certeza inmodificada, es la conciencia neutral de un objeto-imagen" 41 . Esto enfatiza la idea de que una misma imagen perceptivamente captada puede ser modalizada, sustrayéndola así de la esfera de la percepción empírica. Al hacerlo, la imagen deviene autónoma y "libre" y pasa a ser un fictum, esto es, no subordinada al carácter de creencia inherente a la materialidad sensible de su soporte físico: "Donde imagen y tema conscientemente divergen, donde la conciencia de una figuración debe ser vívida, pues entre la imagen y el tema tiene lugar una discrepancia, entonces se separan el objeto-imagen y tema-dela-imagen, y podemos mirar puramente al objeto-imagen, en vez de vivir en el tema-de-la-imagen. En todo caso, mediante el corte de toda simbolización y, por otro lado, mediante el corte de cada unificación con la percepción ponente del ‘entorno de la imagen', obtenemos entonces una percepción pura sin posición”42.

\footnotetext{
41 Hua III/ 1, 251s; Husserl, Ideas I, p. 347.

42 "Wo Bild und Sache bewusstseinsmässig auseinandertreten, wo das Bewusstsein einer Abbildung lebendig sein muss, weil zwischen Bild und Sache Diskrepanz statthat, da scheidet sich Bildobjekt und Bildsujet, und wir können auf das Bildobjekt rein hinsehen, statt im Bildsujet zu
} 
Para el caso concreto de la conciencia de imagen, debemos tener en cuenta que esa efectuación solo puede darse como correlato de una conciencia constituyente: esta es la conciencia de fantasía, la conciencia de "como si" (als ob): "Esta es la diferencia entre el fictum y la imagen: el fictum auténtico aparece directamente en la unidad de la realidad... mientras que la imagen no 'aparece' propiamente alli, sino en su propio espacio, el cual no tiene ningún vínculo directo con la realidad"43. El estatuto fenomenológico de la imagen, por tanto, conlleva efectuar una distinción entre el fictum (al que Husserl identifica con el objeto-imagen ${ }^{44}$ ), esto es, una percepción vaciada de su carácter ponente, y la imagen propiamente "visualizada", que presentifica "algo". La experiencia de la imagen reside en su carácter doblemente irreal, esto es, no propiamente "localizada" en un campo visual que no es ni real ni cuasi-real.

Esta irrealidad es producto de una doble modificación. Debido a su complejidad, esta explicación debe ser necesariamente acompañada por un ejemplo para evitar caer en una exposición innecesariamente abstracta. Tengamos en mente la experiencia de una pieza teatral (si bien esto puede aplicarse, mutatis mutandis, a otras experiencias igualmente ficcionales). Entramos a la sala y ocupamos una butaca. Observamos la luz sobre el escenario, su disposición espacial, podemos dirigir nuestra atención a las butacas de al lado: primero están desocupadas, al cabo de un rato, dos desconocidos se sientan a nuestro lado. En todo momento somos conscientes de lo que vemos, de los sonidos que escuchamos, de las voces, la música, etcétera. Al comenzar la pieza, debemos elegir entre permanecer "fuera" de la pieza o "adentrarnos" en ella. Si optamos por lo primero, mantenemos una actitud cognoscitiva con respecto a nuestro objeto de experiencia, pero renunciamos a la vivencia ficcional para permanecer en la "realidad": vemos a los actores, seguimos sus movimientos sobre las tablas, notamos el juego de las luces, incluso podemos orientar nuestra atención a la escenografía y los atrezos, analizar de qué material están confeccionados, etcétera. Sin embargo, no hacemos vivencia de la historia representada.

leben. Also jedenfalls durch Abschneidung aller Symbolisierung und durch Abschneidung andererseits jeder Vereinheitlichung mit der setzenden Wahnehmung der 'Bildumgebung' erhalten wir eine reine setzungslose Perzeption" (Hua XXIII, p. 467).

${ }_{43}$ "Das ist der Unterschied zwischen Fiktum und Bild, dass das echte Fiktum in der Einheit der Wirklichkeit direkt erscheint... während das Bild eigentlich nicht darin 'erscheint', sondern in einem eigenem Raum, der an sich keine direkte Beziehung hat zum wirklichen" (Hua XXIII, p. 480).

44 "El objeto-imagen es un fictum // Das Bildobjekt ist ein Fiktum" (Hua XXIII, p. 490). 
Por tanto, para pasar de una primera actitud a otra hace falta modalizar nuestra conciencia actual para dar paso a la conciencia de "como si". Entonces convertimos al actor real en un fictum. Cada objeto allí cuasi-percibido (el actor, el telón, la escenografia, los atrezos) se constituye como formando parte de un campo "cuasi-visual". Pero este movimiento no nos adentra por sí solo al "tiempo ficcional" que es creado por la puesta en escena. Sobre esta primera conciencia actual neutralizada, debemos efectuar una segunda modificación para "sumergirnos" en la historia. Es solo por medio de este segundo movimiento que conseguimos "re-plegarnos" a nuestra conciencia imaginaria, haciendo vivencia de la fantasía. Es aquí, en esta esfera, donde propiamente constituimos los objetos imaginarios de la fantasía como haciendo parte de un mundo, el mundo de la fantasia, que en tanto correlato del yo-imaginario está atravesado de su propia temporalidad (el tiempo de la ficción) también imaginariamente constituida.

Así pues, aunque suene paradójico, la experiencia de la irrealidad de la imagen se da por medio de su conexión con la realidad. Esto no quiere decir que la imagen sea al mismo tiempo irreal y real, porque reestableceriamos el conflicto (Widerstreit). Solo apreciamos la imagen como imagen (y no como algo perceptualmente captado) cuando todo el nexo de su campo de aparición deviene también "irreal". Pero la irrealidad de la imagen es vivida como un "ahora" para el yo-imaginario. Es en ese nivel donde se constituye verdaderamente el objeto de la contemplación estética, y no en el nivel del yo-actual, que solo atendería a las cualidades sensibles del objeto perceptualmente captado, inscribiéndolo en el flujo de la conciencia de tiempo interno como presente viviente.

\section{Conclusión}

A lo largo de este artículo he defendido que la fantasía y la conciencia de imagen deben ser entendidas en una relación de género y especie. Si la conciencia de imagen es un subtipo de la conciencia de fantasía (o conciencia de "como si"), la así llamada "conciencia estética", que supone una contemplación "desinteresada" de los objetos, no tiene que ser resultado de ninguna epojé. En primer lugar, porque la contemplación estética conlleva una mezcla de percepción y fantasía, ya que se trataría simplemente de una "desactivación" (neutralización) de los caracteres dóxicos de una nóesis. Sin dejar mencionar otro tipo de elementos o respuestas subjetivas que intervienen en la contemplación, sean del tipo emocional (como el miedo o la empatía), sean de tipo 
axiológico (como las valoraciones cognitivas, morales o estéticas). Sin embargo, esta neutralización no explica por sí sola el desinterés. El "sumergirse" en una obra es un acto de fantasía porque me instala (a mí, al yo fantaseante) en la esfera de la conciencia de "como si". Es aquí, en esta esfera, donde mi conciencia escindida (el yo imaginario o yo-fantaseado) opera como polo constitutivo del objeto fantaseado (una imagen, una ficción, etcétera). Es en este nivel (y no en el anterior, el de la mera conciencia de "como si") donde se asienta la experiencia de fantasía y donde la imagen funda su estatuto fenomenológico: inscrita en un "mundo" del que forma parte, que no es otro que el mundo de la fantasía.

\section{Agradecimientos}

Quisiera agradecer los exhaustivos comentarios de los revisores anónimos, cuyas detalladas y pormenorizadas observaciones han contribuido tanto a mejorar significativamente la redacción de este artículo, como a subsanar las imprecisiones terminológicas y/o conceptuales de la primera versión. Este artículo se benefició del programa de becas de postdoctorado de la Fundação para a Ciência e a Tecnologia de Portugal (SFRH/BPD/118083/2016).

Recibido: $17 / 01 / 2019$

Aceptado: 13/04/2019

\section{Bibliografia}

Aldea, A.S., "Husserl's struggle with mental images: imaging and imagining reconsidered", en: Continental Philosophy Review, 46 (2013), pp. 371-394. https://doi. org/10.1007/s11007-013-9268-7

Bernet, R., Conscience et existence, París : PUF, 2004. https://doi.org/10.3917/puf. berne.2004.01

Bernet, R., Kern, I. y E. Marbach, An Introduction to Husserlian Phenomenology, Evanston: Northwestern University Press, 1993.

Carreño Cobos, J., "The Many Senses of Imagination and the Manifestation of Fiction: A View from Husserl's Phenomenology of Phantasy", en: Husserl Studies 29, 2 (2013), pp. 143-162. https://doi.org/10.1007/s10743-012-9117-2

Cavallaro, M., "The Phenomenon of Ego-splitting in Husserl's Phenomenology of Pure Phantasy", en: Journal of the British Society for Phenomenology, v. 48, 2 (2017), pp. 162-177. https://doi.org/10.1080/00071773.2016.1250436

Conde Soto, F., Tiempo y conciencia en Edmund Husserl, Santiago de Compostela: Servizio de Publicacións da Universidade de Santiago de Compostela, 2012. 
De Warren, N., “Tamino's Eyes, Pamina's Gaze: Husserl's Phenomenology of Image-Consciousness Refashioned", en: Ierna, C., Jacobs, h. y F. Mattens (eds.), Philosophy, Phenomenology, Sciences. Essays in Commemoration of Edmund Husserl, Dordrecht: Springer, 2010, pp. 303-302. https://doi. org/10.1007/978-94-007-0071-0_12

De Warren, N., Husserl and the promise of Time, Cambridge: Cambridge University Press, 2009. https://doi.org/10.1017/CBO9780511657412

Ferencz-Flatz, C., "Gibt es perzeptive Phantasie? Als-ob-Bewusstsein, Widerstreit und Neutralität in Husserls Aufzeichnungen zur Bildbetrachtung", en: Husserl Studies, v. XXV, 3 (2009), pp. 235-253. https://doi.org/10.1007/s10743-009-9062-X

Husserl, E., "Carta de Edmund Husserl a von Hofmannsthal, 12.01.1907", en: Areté, v. XXIX, 2 (2017), pp. 427-430. https://doi.org/10.18800/arete.201702.009

Husserl, E., Ideas relativas a una fenomenología pura y una filosofía fenomenológica. Libro primero. Introducción general a una fenomenología pura, México: Fondo de Cultura Económica, 2013.

Husserl, E., Wahrnehmung und Aufmerksamkeit. Texte aus dem Nachlass (1893-1912), Dordrecht: Springer, 2005. Hua XXXVIII.

Husserl, E., Einführung in die Phänomenologie der Erkenntnis. Vorlesung 1909. Dordrecht: Kluwer, 2005. Hua Mat VII.

Husserl, E., Phantasie, Bildbewusstsein, Erinnerung. Zur Phänomenologie der anschaulichen Vergegenwartigungen. Texte aus dem Nachlass (1898-1925), La Haya: M. Nijhoff, 1980. Hua XXIII.

Husserl, E., Ideen zu einer reinen Phänomenologie und phänomenologischen Philosophie. Erstes Buch: Allgemeine Einführungin die reine Phänomenologie 1. Halbband: Text der 1.-3. Auflage - Nachdruck, 1977. Hua III/1. https://doi. org/10.1007/978-94-010-1041-2

Husserl, E., Zur Phänomenologie des inneren Zeitbewusstesens (1893-1917), La Haya: M. Nijhoff, 1969. Hua X. https://doi.org/10.1007/978-94-015-3945-6

Husserl, E., Erste Philosophie (1923/4). Zweiter Teil: Theorie der phänomenologischen Reduktion, La Haya: M. Nijhoff, 1959. Hua VIII.

Jansen, J., "Phantasy's Systematic Place in Husserl's Work", en: Bernet, R., Welton, D. \& G. Zavota (eds.), Edmund Husserl. Critical Assessments of Leading Philosophers, v. III, Londres/Nueva York: Routledge, 2005, pp. 221-243.

Lohmar, D., "Die Entwicklung des husserlschen Konstitutionsmodells von Auffassung und Inhalt”, en: Studia Univeristates Babeş-Bolyai. Philosophia, v. LIV, 2 (2009), pp. 3-19.

Luft, S., "Die Konkretion des Ich und das Problem der Ichspaltung in Husserls phänomenologischer Reduktion", en: R. Kühn y M. Staudigl (eds.), Epoché und Reduktion: Formen und Praxis der Reduktion in der Phänomenologie, Würzburg: Königshausen \& Neumann, 2003, pp. 31-49.

Mendoza-Canales, R. "Estructura intencional y libre fantasía en Ideas I de Edmund Husserl”, en: Anales del Seminario de Historia de la Filosofia, v. XXXVI, 2 (2019), pp. 421-439. https://doi.org/10.5209/ashf.64454 
Mendoza-Canales, R., "La fenomenología como teoría del conocimiento: Husserl sobre la epojé y la modificación de neutralidad", en: Revista de filosofia, v. XLIII, 1 (2018), pp. 121-138. https://doi.org/10.5209/RESF.60203

Mendoza-Canales, R., "Ver y no creer: imaginación, fantasía y conciencia de 'como si' en la fenomenología de Husserl”, en: Phainomenon, 27 (2018), pp. 69-97.

Ricoeur, P., La Memoria, la historia, el olvido, Madrid: Trotta, 2003.

Scanziani, A., "Intencionalidad y atención: el abordaje husserliano de la atención en relación con la intencionalidad y su caracterización como "mentar"“, en: Ideas. Revista de filosofia moderna y contemporánea, 7, pp. 48-82.

Serrano de Haro, A., "Pain Experience and Structures of Attention: A Phenomenological Approach”, en: van Rysewyk, S. (ed.), Meanings of Pain, Dordrecht: Springer, 2016, pp. 165-180. https://doi.org/10.1007/978-3-319-49022-9_10

Shum, P., "The Evolution and Implications of Husserl's Account of the Imagination", en: Husserl Studies, v. XXXI, 3 (2015), pp. 213-236. https://doi.org/10.1007/ s10743-015-9175-3

Schumann, K., Husserks Chronik. Denk-und Lebensweg Edmund Husserls, La Haya: M. Nijhoff, 1981. Hua Dok I. 